\title{
Cholesterol remnants and triglycerides are associated with decreased myocardial function in patients with type 2 diabetes
}

Peter Godsk Jørgensen 1,2*, Magnus Thorsten Jensen', Tor Biering-Sørensen', Rasmus Mogelvang', Søren Galatius ${ }^{1}$, Thomas Fritz-Hansen ${ }^{1}$, Peter Rossing ${ }^{2,3,4}$, Tina Vilsbø $\|^{2,5}$ and Jan Skov Jensen ${ }^{1,2}$

\begin{abstract}
Background: Recently, genetic studies have suggested a causal relationship between cholesterol remnants and ischemic heart disease. We aimed to determine whether cholesterol remnants and its marker, triglyceride levels, are associated with cardiac function as determined by sensitive echocardiographic measures in a population of patients with type 2 diabetes.
\end{abstract}

Methods: Comprehensive echocardiography including 2D-speckle tracking echocardiography was performed on a representative sample of 924 patients with type 2 diabetes -730 of whom were treated with statins. These were recruited from two large secondary care centers.

Results: In multivariable analyses, triglycerides and cholesterol remnants were not associated with left ventricular ejection fraction, but with subtle measures of systolic function, including global longitudinal strain by speckle tracking and longitudinal displacement by tissue Doppler echocardiography: global longitudinal strain $[0.33 \%(0.14)$, $p=0.02$ per doubling in cholesterol remnants and $0.28 \%(0.13), p=0.03$ per doubling in triglyceride levels] and with longitudinal displacement $[-0.25 \mathrm{~mm}(0.10), p=0.01$ per doubling in cholesterol remnants and $-0.25 \mathrm{~mm}(0.09)$, $p=0.005$ per doubling in triglyceride levels]. Subgroup analyses of patients receiving statin therapy and patients without known heart disease revealed similar results, but the association was not present in patients with known heart disease.

Conclusion: In patients with type 2 diabetes, subtle decrease in left ventricular function is present with increasing levels of cholesterol remnants and triglyceride levels indicating an effect of these on cardiac function that is not detectable by conventional echocardiography.

Keywords: Type 2 diabetes, Lipids, Echocardiography

\section{Background}

In patients with type 2 diabetes, advances in medical treatment-including aggressive lipid-lowering therapy with statins and life-style interventions-have led to a decrease in mortality from cardiovascular disease [1-3]. However, patients with type 2 diabetes are still prone to cardiovascular disease and with an increasing number of patients with type 2 diabetes, the burden of cardiovascular disease

\footnotetext{
*Correspondence: petergodsk@gmail.com

${ }^{1}$ Department of Cardiology, Herlev and Gentofte Hospital, University of Copenhagen, Kildegårdsvej 28, 2900 Hellerup, Denmark

Full list of author information is available at the end of the article
}

persists [4]. The residual risk may in part be attributable to lipoproteins other than LDL-cholesterols that are the target of statin therapy, and recently, genetic studies have suggested a causal relationship between cholesterol remnants and ischemic heart disease $[5,6]$. Cholesterol remnants-defined as cholesterol content of the largest, triglyceride-rich proteins, VLDL, IDL and chylomicrons-are reversely related to HDL cholesterol and have gained renewed interest in the light of the disappointing results of therapies aimed at HDL cholesterol.

Remnant cholesterol possibly exerts its effect on the diabetic myocardium by at least 2 mechanisms. First, the 
remnant lipoproteins can enter the intima of the coronary arteries causing accumulation of cholesterol $[7,8]$ ultimately leading to at least partly obstructive disease affecting mainly the subendocardial myocardial fibers that are most susceptible to decreased coronary flow and are the main myocardial fibers responsible for left ventricular longitudinal function [9]. Second, action of the enzyme lipoprotein lipase on the surface of the remnant particle leads to liberation of free fatty acids in the proximity of the myocardial cells [10] which can lead to accumulation of free fatty acids and triglycerides in the myocytes. Here, the substrate of metabolism is altered to almost complete reliance of fatty acids, which in turn by complex pathways is thought to lead to diabetic cardiomyopathy $[11,12]$. In accordance, triglycerides-which are markers of cholesterol remnants $[6,13]$-have been shown to predict heart failure in patients with diabetes, but not in patients without diabetes $[14,15]$.

While cholesterol remnants are considered a risk factor for ischemic heart disease, their relation to myocardial structure and function is unknown. Therefore, we examined the effect of cholesterol remnants and triglycerides on myocardial structure and function in a population of patients with type 2 diabetes using comprehensive echocardiography including 2D speckle tracking echocardiography. This is a sensitive method used to identify subtle changes in cardiac function that we have shown to be reduced in patients with type 2 diabetes [16] and has been shown to predict cardiovascular events in these patients [17]. In addition, to address if statin treatment modifies the association of cholesterol remnants and triglyceride with myocardial structure and function, we performed a subgroup analysis on patients already receiving statin therapy.

\section{Methods}

The Thousand \& 2 echocardiographic study was initiated in 2011, where a representative sample of patients from two large secondary care centers (The Steno Diabetes Center and Center for Diabetes Research, Herlev and Gentofte Hospital, University of Copenhagen) in the Copenhagen region were invited to participate. Details are described elsewhere [18]. In brief, from November 2011 through to December 2013, 2158 patients were invited and 1030 participated (participation rate $47.8 \%$ ). Prior to the study visit, a questionnaire was sent to the patients with among others questions on current medication, prior heart disease (myocardial infarction, percutaneous coronary intervention, coronary artery bypass grafting, congestive heart failure and atrial fibrillation), prior stroke and peripheral artery disease, family history of coronary heart disease, smoking habits, height and weight. At the visit, the questionnaire was reviewed with the patient by PGJ. In the present study, we excluded patients with atrial fibrillation during the echocardiographic examination and/or severe valve disease/previous heart valve surgery $(\mathrm{n}=96)$ as well as patients where neither cholesterol remnants nor triglyceride levels $(n=10)$ were available. Blood pressure was measured in the supine position after at least $15 \mathrm{~min}$ of rest. Body mass index (BMI) was defined as weight $(\mathrm{kg}) /$ height $(\mathrm{m})^{2}$.

\section{Cholesterol remnants and triglyceride}

LDL-cholesterol, HDL-cholesterol and total-cholesterol were measured in routine blood samples using standard hospitals assays at each visit at Center for Diabetes research, Herlev and Gentofte Hospital, University of Copenhagen or at the visit at Steno Diabetes Center preceding the study visit. In Denmark, non-fasting measurements of lipids is the standard, however, in a subset of the patients (14\%), only fasting lipids were available. Direct measurement of cholesterol remnants is difficult, but a simple approximation was obtained by calculating the sum of VLDL, IDL and chylomicrons with the formula cholesterol remnants $=$ total-cholesterol - HDL-cholesterol - LDL-cholesterol. This method is easy with the use of standard lipid measurements and has been used in previous studies $[5,6,13,19]$.

\section{Other laboratory analyses}

Hemoglobin $A_{1 c}$ and creatinine levels were obtained from routine blood samples at either center as decribed above. Urine albumin/creatinine ratio or $24 \mathrm{~h}$ urine albumin excretion rate is performed at least annually at both centers. Microalbuminuria was defined as urine albumin/ creatinine ratio between 30 and $300 \mathrm{mg} / \mathrm{g}$ or urine albumin excretion rate between 30 and $300 \mathrm{mg} /$ day, and macroalbuminuria as urine albumin/creatinine ratio above $300 \mathrm{mg} / \mathrm{g}$ or urine albumin excretion rate above $300 \mathrm{mg} /$ day in two consecutive measurements.

\section{Echocardiography}

Echocardiography was performed with General Electrics, Vivid 7 and Vivid 9 (Vingmed ultrasound, Horten, Norway) and digitally stored. Three consecutive heart cycles were recorded for each view. The Thousand\&2 echocardiograms ( $>95 \%$ ) were made by PGJ and all offline analyses were performed using General Electrics EchoPac software BT13 by on physician (PGJ). Chamber quantification was done in accordance with the recommendations of the European Association of Echocardiography and the American Society of Echocardiography [20]. Left ventricular (LV) mass was calculated using the formula $\mathrm{LV}$ mass $=0.8 \times\{1.04[(\mathrm{LV}$ internal diameter + posterior wall thickness + septal wall thickness $)^{3}-(\mathrm{LV}$ internal diameter $\left.\left.)^{3}\right]\right\}+0.6 \mathrm{~g}$ and indexed according to 
height ${ }^{2.7}$. Left atrial (LA) end-systolic and end-diastolic volumes were calculated using the area-length method, where left atrial volume $=8 / 3 \times \pi$ (LA area in 4 chamber view $\times$ LA area in 2 chamber view/shortest long axis length in either view) and indexed to body surface area. Mitral inflow velocities [peak early (E) and peak atrial (A)] and deceleration time of the $\mathrm{E}$ wave were measured in the 4-chamber view using pulsed-wave Doppler with the sample volume placed between the tips of the mitral valve leaflets. Early diastolic myocardial velocity (e') was measured in 4-chamber view with pulsed-wave tissue velocity Doppler with the sample volume placed in the septal and lateral mitral annulus.

\section{Left ventricular systolic function}

LV ejection fraction was assessed using Simpson's biplane method. Speckle tracking echocardiography was performed on 2D grey scale recordings of 4-, 2- and 3-chamber apical views and analyzed off-line. In brief, the software identified speckles within a specified part of the myocardium and tracked these from frame to frame. A semi-automated function traced the myocardium in the beginning of the systole and allowed for manual modification of the region of interest to ensure only speckles in the myocardium were tracked throughout the cardiac cycle. Visual inspection of the tracking curves ensured accurate tracking of the speckles and segments where the tracking was assessed inadequate were excluded from the analyses. Doing this for each segment of the left ventricle a measurement of longitudinal function or deformation expressed as peak systolic strain was obtained for each segment and for 3 layers of each segment. In the present study, midmyocardial strain was used and global longitudinal strain (GLS) was calculated as the average peak systolic strain of the 18 midmyocardial segments. If accurate tracking was obtained in less than 12 of the 18 midmyocardial segments because of poor image quality, the echocardiogram was excluded from the analyses (15.3\% of the examinations). As a sensitivity measure to complement the strain measurements of longitudinal cardiac function, longitudinal displacement obtained by color tissue Doppler imaging was performed. Longitudinal displacement was calculated as the average of the integral of the velocity curves during ejection phase of sample volumes placed in each of the mitral annular positions. This measure has previously been validated and demonstrated to be a very accurate measure of mitral annular plane excursion [21].

\section{Statistics}

Both the distribution of the triglyceride levels and the cholesterol remnant levels were markedly skewed, so they were logarithmically transformed in the analyses using the binary logarithm $\left[\log _{2}\right.$ (triglyceride) and $\log _{2}$ (cholesterol remnants)] after which both were normally distributed. Linear regression analyses were used to examine the effect of the logarithmically transformed levels of triglyceride and cholesterol remnants on measures of cardiac structure, systolic and diastolic function. Multivariable models were constructed with age, sex, hemoglobin $\mathrm{A}_{1 \mathrm{c}}$, body mass index, systolic blood pressure and albuminuria as covariates. P-values less than 0.05 on twosided tests were considered significant. Statistics were calculated using R for Mac, version 2.15.3 (R Project for Statistical Computing, Vienna University of Economics and Business Administration, Wien, Austria).

\section{Results}

A total of 924 patients were identified of whom 730 were receiving statin therapy. The study population's clinical and echocardiographic characteristics are shown in Table 1 and Additional file 1: Table S1. Notably, both groups and in particular the patients receiving statin therapy had low LDL-cholesterol levels.

\section{Structural and diastolic measurements}

Structural and diastolic echocardiographic findings of the entire population including patients not receiving statin therapy is shown in Tables 2 and 3. For all patients as well as the subgroup of patients receiving statin therapy, increasing levels of $\log _{2}$ (triglyceride) were associated with increasing LV mass, LV wall thicknesses and decreasing LA size in univariable analyses, but this association was attenuated in multivariable analyses except for LA size. Regarding dynamic diastolic measurements, measures of early diastolic filling, including peak $\mathrm{E}$ velocity, lateral and septal e' were only significantly associated in multivariable adjusted analyses with both $\log _{2}$ (cholesterol remnant) and $\log _{2}$ (triglyceride). Regarding LDL-cholesterol, LV wall thicknesses were inversely related to increasing levels of $\log _{2}$ (LDL-cholesterol), but none of the diastolic measurements were associated with increasing levels of $\log _{2}$ (LDL-cholesterol), Additional file 1: Table S2. A subgroup analysis of patients with and without known coronary heart disease showed that the structural and diastolic changes associated with $\log _{2}$ (cholesterol remnant) and $\log _{2}$ (triglyceride) were driven by patients without known coronary heart disease. An exception was septal e' that was significantly associated with $\log _{2}$ (cholesterol remnants) in patients with known coronary heart disease whereas lateral e' was associated with both $\log _{2}$ (cholesterol remnant) and $\log _{2}$ (triglyceride) in patients without coronary heart disease. 
Table 1 Study population characteristics

\begin{tabular}{|c|c|c|}
\hline & $\begin{array}{l}\text { All } \\
n=924\end{array}$ & $\begin{array}{l}\text { Receiving statin therapy } \\
n=730\end{array}$ \\
\hline \multicolumn{3}{|l|}{ Clinical } \\
\hline Age (years) & $65[58,70]$ & $65[59,70]$ \\
\hline Male sex, n (\%) & $597(65)$ & $486(67)$ \\
\hline Diabetes duration (years) & $11[6,17]$ & $11[6,17]$ \\
\hline Body mass index $\left(\mathrm{kg} / \mathrm{m}^{2}\right)$ & $29[26,33]$ & $30[27,33]$ \\
\hline Systolic blood pressure (mmHg) & $136(17)$ & $135(16)$ \\
\hline Diastolic blood pressure $(\mathrm{mmHg})$ & $80(11)$ & $80(10)$ \\
\hline Known coronary heart disease n (\%) & $162(18)$ & $140(19)$ \\
\hline \multicolumn{3}{|l|}{ Lipids } \\
\hline Total cholesterol (mmol/l) & $4.1[3.5,4.8]$ & $3.9[3.4,4.5]$ \\
\hline Low density cholesterol (mmol/l) & $2.0[1.6,2.6]$ & $1.8[1.5,2.3]$ \\
\hline High density cholesterol (mmol/l) & $1.2[1.0,1.4]$ & $1.2[1.0,1.4]$ \\
\hline Cholesterol remnants (mmol/l) & $0.8[0.5,1.1]$ & $0.7[0.5,1.0]$ \\
\hline Triglyceride $(\mathrm{mmol} / \mathrm{l})$ & $1.7[1.2,2.4]$ & $1.7[1.2,2.4]$ \\
\hline \multicolumn{3}{|l|}{ Other laboratory values } \\
\hline Albuminuria (\%) & $212(23.3)$ & $165(22)$ \\
\hline Microalbuminuria (\%) & $149(16)$ & $116(16)$ \\
\hline Macroalbuminuria (\%) & $63(7)$ & $49(7)$ \\
\hline Creatinine $(\mu \mathrm{mol} / \mathrm{l})$ & $78[65,96]$ & $78[66,96]$ \\
\hline Haemoglobin $A_{1 c}(\%)$ & $55[48,66]$ & $54[48,65]$ \\
\hline Haemoglobin $A_{1 c}(\mathrm{mmol} / \mathrm{mol})$ & $7.2[6.5,8.2]$ & $7.1[6.5,8.1]$ \\
\hline \multicolumn{3}{|l|}{ Medication } \\
\hline Statins, n (\%) & $730(79)$ & - \\
\hline Metformin, n (\%) & $670(73)$ & $552(76)$ \\
\hline DPP4 inhibitors, n (\%) & $88(10)$ & $71(10)$ \\
\hline Sulfonylurea, n (\%) & $142(15)$ & $107(15)$ \\
\hline Glucagon-like peptide-1 receptor agonists, n (\%) & $226(25)$ & $189(26)$ \\
\hline Insulin, n (\%) & $428(46)$ & $334(46)$ \\
\hline Beta blockers, n (\%) & $221(24)$ & $186(26)$ \\
\hline Angiotensin-converting enzyme inhibitors, n (\%) & $354(38)$ & $297(41)$ \\
\hline Angiotensin II receptor blockers, n (\%) & $359(40)$ & $298(41)$ \\
\hline Calcium antagonists, n (\%) & $294(32)$ & $250(34)$ \\
\hline Diuretics, n (\%) & $452(49)$ & $376(52)$ \\
\hline Antiplatelets, n (\%) & $607(66)$ & $508(70)$ \\
\hline
\end{tabular}

Continuous traits are reported as mean (standard deviation) or median [interquartile range] in case of non-normal distribution

\section{Systolic measurements}

Results from echocardiographic systolic measurements are shown in Table 4. For all patients as well as the subgroup of patients receiving statin therapy conventional measurement of systolic function in the form of ejection fraction by Simpson's biplane method was not associated with neither $\log _{2}$ (cholesterol remnant) nor $\log _{2}$ (triglyceride). However, for all patients, GLS was both uni- and multivariably associated with both $\log _{2}$ (cholesterol remnants) and $\log _{2}$ (triglyceride). The same was the case for longitudinal displacement measured by color tissue Doppler, though the association with $\log _{2}$ (cholesterol remnants) attenuated in the subgroup analysis of patients receiving statin therapy. Thus, two independent measurements of both LV longitudinal function both indicated decreased function with increasing levels of $\log _{2}$ (cholesterol remnant) and $\log _{2}$ (triglyceride). Similar results were found in the subgroup of patients receiving statin therapy, though some of the results were only borderline significant. Regarding LDL-cholesterol, there was 
Table 2 Structural changes in relation to $\log _{2}$ (cholesterol remnants) and $\log _{2}$ (triglyceride)

\begin{tabular}{|c|c|c|c|c|c|c|c|c|}
\hline & \multicolumn{4}{|c|}{$\log _{2}$ (cholesterol remnants) } & \multicolumn{4}{|c|}{$\log _{2}$ (triglyceride) } \\
\hline & \multicolumn{2}{|l|}{ Univariable } & \multicolumn{2}{|l|}{ Multivariable } & \multicolumn{2}{|c|}{ Univariable } & \multicolumn{2}{|l|}{ Multivariable } \\
\hline & $\begin{array}{l}\beta \text {-coefficient } \\
\text { (std error) }\end{array}$ & $P$ value & $\begin{array}{l}\beta \text {-coefficient } \\
\text { (std error) }\end{array}$ & $P$ value & $\begin{array}{l}\beta \text {-coefficient } \\
\text { (std error) }\end{array}$ & $P$ value & $\begin{array}{l}\beta \text {-coefficient } \\
\text { (std error) }\end{array}$ & $P$ value \\
\hline \multicolumn{9}{|l|}{ All patients } \\
\hline $\begin{array}{l}\text { Left ventricular mass } \\
\text { index }\left(\mathrm{g} / \mathrm{m}^{2.7}\right)\end{array}$ & $0.6(0.5)$ & 0.27 & $-0.5(0.5)$ & 0.36 & $1.1(0.5)$ & 0.03 & $-0.1(0.5)$ & 0.81 \\
\hline $\begin{array}{l}\text { Interventricular } \\
\text { septum diameter } \\
(\mathrm{mm})\end{array}$ & $0.21(0.08)$ & 0.01 & $0.01(0.08)$ & 0.90 & $0.26(0.08)$ & $<0.001$ & $0.04(0.07)$ & 0.58 \\
\hline $\begin{array}{l}\text { Left ventricular } \\
\text { internal diameter } \\
(\mathrm{mm})\end{array}$ & $-0.21(0.29)$ & 0.47 & $-0.47(0.30)$ & 0.11 & $-0.04(0.26)$ & 0.89 & $-0.37(0.28)$ & 0.18 \\
\hline $\begin{array}{l}\text { Posterior wall } \\
\text { diameter (mm) }\end{array}$ & $0.16(0.07)$ & 0.03 & $0.01(0.07)$ & 0.90 & $0.25(0.07)$ & $<0.001$ & $0.07(0.06)$ & 0.28 \\
\hline $\begin{array}{l}\text { Left atrial end } \\
\text { systolic volume } \\
\text { index }\left(\mathrm{ml} / \mathrm{m}^{2}\right)\end{array}$ & $-1.61(0.39)$ & $<0.001$ & $-1.41(0.41)$ & 0.001 & $-1.29(0.35)$ & $<0.001$ & $-1.19(0.37)$ & 0.002 \\
\hline \multicolumn{9}{|c|}{ In patients receiving statin therapy } \\
\hline $\begin{array}{l}\text { Left ventricular mass } \\
\text { index }\left(\mathrm{g} / \mathrm{m}^{2.7}\right)\end{array}$ & $0.7(0.6)$ & 0.24 & $-0.3(0.6)$ & 0.56 & $1.1(0.5)$ & 0.04 & $-0.1(0.5)$ & 0.86 \\
\hline $\begin{array}{l}\text { Interventricular } \\
\text { septum diameter } \\
(\mathrm{mm})\end{array}$ & $0.22(0.09)$ & 0.02 & $0.04(0.09)$ & 0.67 & $0.29(0.09)$ & $<0.001$ & $0.08(0.08)$ & 0.35 \\
\hline $\begin{array}{l}\text { End diastolic internal } \\
\text { diameter (mm) }\end{array}$ & $-0.30(0.33)$ & 0.36 & $-0.58(0.34)$ & 0.08 & $-0.17(0.30)$ & 0.57 & $-0.53(0.31)$ & 0.09 \\
\hline $\begin{array}{l}\text { Posterior wall } \\
\text { diameter (mm) }\end{array}$ & $0.17(0.08)$ & 0.04 & $0.04(0.08)$ & 0.62 & $0.26(0.07)$ & $<0.001$ & $0.10(0.07)$ & 0.17 \\
\hline $\begin{array}{l}\text { Left atrial end } \\
\text { systolic volume } \\
\text { index }\left(\mathrm{ml} / \mathrm{m}^{2}\right)\end{array}$ & $-1.73(0.45)$ & $<0.001$ & $-1.47(0.47)$ & 0.002 & $-1.44(0.40)$ & $<0.001$ & $-1.33(0.43)$ & 0.002 \\
\hline
\end{tabular}

Multivariable model adjusted for age, sex, hemoglobin $\mathrm{A}_{1 c^{\prime}}$ body mass index, systolic blood pressure and albuminuria

Italic text indicates $\mathrm{P}<0.05$

no association between $\log _{2}$ (LDL-cholesterol) and longitudinal function expressed as either GLS or longitudinal displacement, Additional file 1: Table S2.

In a subgroup analysis of patients with and without known coronary heart disease, the association was both uni- and multivariably present only in patients without known coronary heart disease, Additional file 1: Tables S3 and S4.

Figures 1 and 2, show the predicted value with $95 \%$ confidence interval of GLS and longitudinal displacement for increasing levels of cholesterol remnants and triglyceride levels respectively on the original scale for both all patients and patients receiving statin therapy as well as the distribution of cholesterol remnant and triglyceride levels in all patients and patients receiving statin therapy.

\section{Discussion}

This study is the first to demonstrate that increasing levels of cholesterol remnants and triglycerides-which are markers of cholesterol remnants-are associated with subtle changes in LV systolic function expressed as GLS and longitudinal displacement in patients with type 2 diabetes-even when receiving statin therapy. This association was not present with increasing levels of LDLcholesterol, which was adequately treated in this patient population. So, even despite having treated LDL-cholesterol to low levels, we were able to detect a relationship between increasing levels of cholesterol remnants and triglycerides and decreasing longitudinal LV function indicating that the detrimental effect of dyslipidemia on the heart is not exhausted with intensive statin therapy. These findings support the notion of cholesterol remnants as a potential therapeutic target in addition to statin therapy in these patients.

We also found, that the association was only present in patients without known coronary heart disease, which is probably because the effect of ischemia and infarction overshadows the effect of the triglycerides and cholesterol remnants on LV myocardial function or possibly because of lack of power in this cohort. 
Table 3 Diastolic changes in relation to $\log _{2}$ (cholesterol remnants) and $\log _{2}$ (triglyceride) in patients with type 2 diabetes

\begin{tabular}{|c|c|c|c|c|c|c|c|c|}
\hline & \multicolumn{4}{|c|}{$\log _{2}$ (cholesterol remnants) } & \multicolumn{4}{|c|}{$\log _{2}$ (triglyceride) } \\
\hline & \multicolumn{2}{|l|}{ Univariable } & \multicolumn{2}{|l|}{ Multivariable } & \multicolumn{2}{|c|}{ Univariable } & \multicolumn{2}{|l|}{ Multivariable } \\
\hline & $\begin{array}{l}\beta \text {-coefficient } \\
\text { (std error) }\end{array}$ & $P$ value & $\begin{array}{l}\beta \text {-coefficient } \\
\text { (std error) }\end{array}$ & $P$ value & $\begin{array}{l}\beta \text { coefficient } \\
\text { (std error) }\end{array}$ & $P$ value & $\begin{array}{l}\beta \text {-coefficient } \\
\text { (std error) }\end{array}$ & $P$ value \\
\hline \multicolumn{9}{|l|}{ All patients } \\
\hline Peak E velocity (m/s) & $-0.01(0.01)$ & 0.12 & $-0.03(0.01)$ & 0.006 & $-0.01(0.01)$ & 0.09 & $-0.03(0.01)$ & 0.002 \\
\hline Peak A velocity (m/s) & $-0.003(0.01)$ & 0.76 & $-0.001(0.01)$ & 0.93 & $-0.01(0.01)$ & 0.51 & $-0.003(0.01)$ & 0.72 \\
\hline E/A ratio & $-0.01(0.01)$ & 0.48 & $-0.03(0.01)$ & 0.05 & $-0.01(0.01)$ & 0.53 & $-0.03(0.01)$ & 0.03 \\
\hline $\begin{array}{l}\text { E deceleration time } \\
(\mathrm{ms})\end{array}$ & $2.8(3.5)$ & 0.41 & $3.3(3.6)$ & 0.36 & $0.8(3.1)$ & 0.81 & $1.5(3.3)$ & 0.65 \\
\hline Lateral e' $(\mathrm{cm} / \mathrm{s})$ & $-0.18(0.12)$ & 0.13 & $-0.25(0.11)$ & 0.02 & $-0.19(0.11)$ & 0.07 & $-0.27(0.10)$ & 0.008 \\
\hline Septal e' $(\mathrm{cm} / \mathrm{s})$ & $-0.12(0.09)$ & 0.19 & $-0.18(0.08)$ & 0.03 & $-0.10(0.08)$ & 0.22 & $-0.17(0.08)$ & 0.03 \\
\hline $\mathrm{E} / \mathrm{e}_{\text {mean }}^{\prime}$ & $0.11(0.20)$ & 0.58 & $0.01(0.20)$ & 0.97 & $0.08(0.18)$ & 0.65 & $-0.02(0.18)$ & 0.93 \\
\hline \multicolumn{9}{|c|}{ Patients receiving statin therapy } \\
\hline $\begin{array}{l}\text { Peak E velocity } \\
(\mathrm{cm} / \mathrm{s})\end{array}$ & $-0.02(0.01)$ & 0.08 & $-0.03(0.01)$ & 0.006 & $-0.02(0.01)$ & 0.08 & $-0.03(0.01)$ & 0.004 \\
\hline $\begin{array}{l}\text { Peak A velocity } \\
(\mathrm{cm} / \mathrm{s})\end{array}$ & $-0.002(0.01)$ & 0.82 & $-0.0003(0.01)$ & 0.98 & $-0.01(0.01)$ & 0.57 & $-0.002(0.01)$ & 0.86 \\
\hline E/A ratio & $-0.02(0.01)$ & 0.25 & $-0.03(0.01)$ & 0.02 & $-0.01(0.01)$ & 0.36 & $-0.03(0.01)$ & 0.02 \\
\hline $\begin{array}{l}\text { E deceleration time } \\
(\mathrm{ms})\end{array}$ & $3.8(3.9)$ & 0.33 & $3.57(4.11)$ & 0.39 & $1.3(3.5)$ & 0.72 & $1.1(3.7)$ & 0.77 \\
\hline Lateral e' $(\mathrm{cm} / \mathrm{s})$ & $-0.07(0.13)$ & 0.59 & $-0.19(0.13)$ & 0.13 & $-0.10(0.12)$ & 0.37 & $-0.21(0.11)$ & 0.07 \\
\hline Septal e' $(\mathrm{cm} / \mathrm{s})$ & $-0.07(0.10)$ & 0.49 & $-0.17(0.10)$ & 0.08 & $-0.10(0.09)$ & 0.27 & $-0.18(0.09)$ & 0.04 \\
\hline$E / e_{\text {mean }}^{\prime}$ & $-0.10(0.22)$ & 0.65 & $-0.17(0.22)$ & 0.44 & $-0.06(0.20)$ & 0.78 & $-0.13(0.20)$ & 0.53 \\
\hline
\end{tabular}

Multivariable model adjusted for age, sex, hemoglobin $\mathrm{A}_{1,}$, body mass index, systolic blood pressure and albuminuria Italic text indicates $\mathrm{P}<0.05$

Table 4 Systolic changes in relation to $\log _{2}$ (cholesterol remnants) and $\log _{2}$ (triglyceride) in patients with type 2 diabetes

\begin{tabular}{|c|c|c|c|c|c|c|c|c|}
\hline & \multicolumn{4}{|c|}{$\log _{2}$ (cholesterol remnants) } & \multicolumn{4}{|c|}{$\log _{2}$ (triglyceride) } \\
\hline & \multicolumn{2}{|l|}{ Univariable } & \multicolumn{2}{|l|}{ Multivariable } & \multicolumn{2}{|l|}{ Univariable } & \multicolumn{2}{|l|}{ Multivariable } \\
\hline & $\begin{array}{l}\beta \text {-coefficient } \\
\text { (std error) }\end{array}$ & P value & $\begin{array}{l}\beta \text {-coefficient } \\
\text { (std error) }\end{array}$ & P value & $\begin{array}{l}\beta \text {-coefficient } \\
\text { (std error) }\end{array}$ & P value & $\begin{array}{l}\beta \text {-coefficient } \\
\text { (std error) }\end{array}$ & $P$ value \\
\hline \multicolumn{9}{|l|}{ All patients } \\
\hline Ejection fraction (\%) & $-0.7(0.4)$ & 0.09 & $-0.4(0.4)$ & 0.31 & $-0.6(0.4)$ & 0.09 & $-0.3(0.4)$ & 0.42 \\
\hline $\begin{array}{l}\text { Global longitudinal } \\
\text { systolic strain (\%) }\end{array}$ & $0.40(0.13)$ & 0.003 & $0.33(0.14)$ & 0.02 & $0.34(0.12)$ & 0.004 & $0.28(0.13)$ & 0.03 \\
\hline $\begin{array}{l}\text { Longitudinal dis- } \\
\text { placement (mm) }\end{array}$ & $-0.25(0.09)$ & 0.007 & $-0.25(0.10)$ & 0.01 & $-0.25(0.08)$ & 0.003 & $-0.25(0.09)$ & 0.005 \\
\hline \multicolumn{9}{|c|}{ Patients receiving statin therapy } \\
\hline Ejection fraction (\%) & $-0.7(0.4)$ & 0.12 & $-0.4(0.5)$ & 0.43 & $-0.5(0.4)$ & 0.18 & $-0.1(0.4)$ & 0.72 \\
\hline $\begin{array}{l}\text { Global longitudinal } \\
\text { systolic strain (\%) }\end{array}$ & $0.38(0.15)$ & 0.01 & $0.32(0.16)$ & 0.05 & $0.33(0.14)$ & 0.01 & $0.29(0.15)$ & 0.05 \\
\hline $\begin{array}{l}\text { Longitudinal dis- } \\
\text { placement (mm) }\end{array}$ & $-0.20(0.11)$ & 0.07 & $-0.20(0.11)$ & 0.06 & $-0.22(0.09)$ & 0.02 & $-0.22(0.10)$ & 0.03 \\
\hline
\end{tabular}

Multivariable model adjusted for age, sex, hemoglobin $\mathrm{A}_{1 c^{\prime}}$, body mass index, systolic blood pressure and albuminuria

Italic text indicates $\mathrm{P}<0.05$

Dyslipidemia, LV changes and risk of heart failure

Animal models have linked cholesterol levels with changes in both diastolic and systolic performance [22,
23] and one study found an association with LV ejection fraction and HDL-cholesterol in patients with angina pectoris [24]. In a recent paper, Mochizuki et al. 
Patients with type 2 diabetes
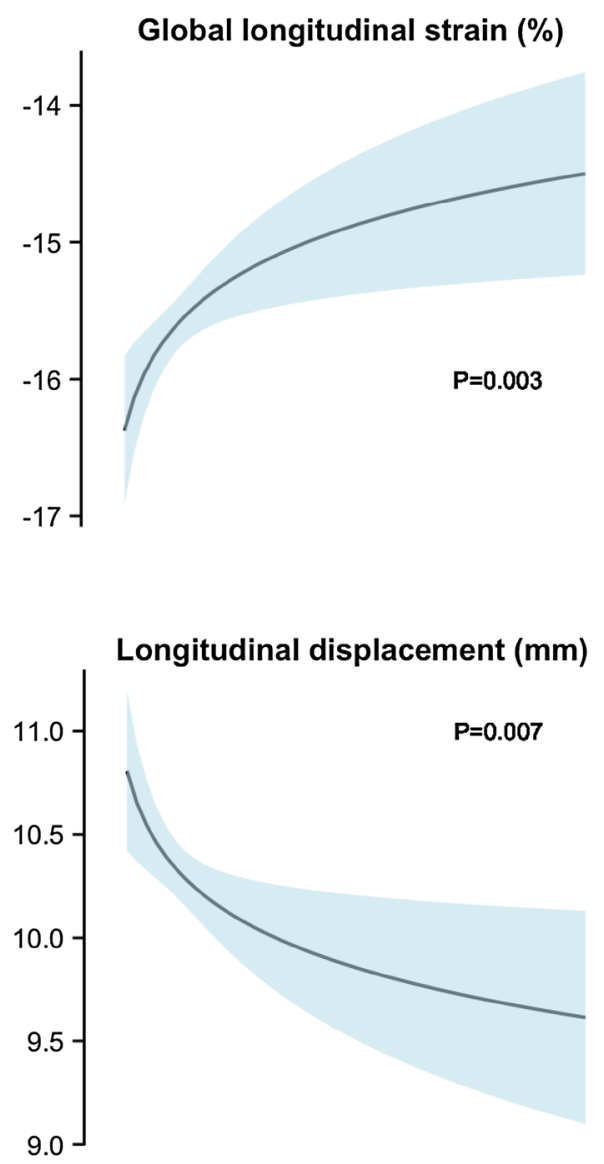

Density (n)

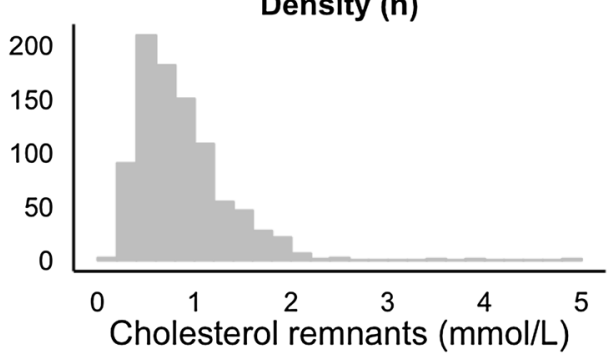

Patients with type 2 diabetes and receiving statin therapy
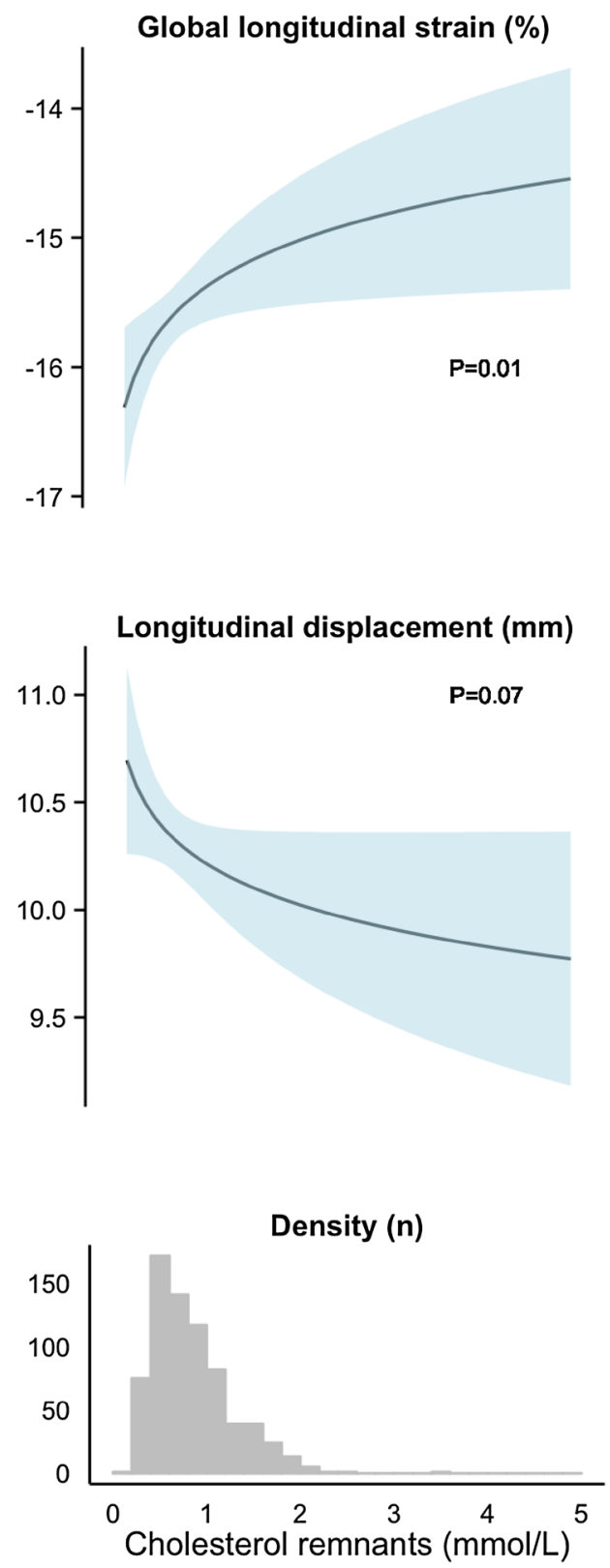

Fig. 1 Association of cholesterol remnants levels to global longitudinal strain and longitudinal displacement in patients with type 2 diabetes and in patients with type 2 diabetes receiving statin therapy. The upper curves depict the predicted value with $95 \%$ confidence interval of GLS and longitudinal displacement for increasing levels of cholesterol remnants on the original scale for both all patients and patients receiving statin therapy. The lower histograms are the distribution of cholesterol remnants in all patients and patients receiving statin therapy. Cholesterol remnants were calculated by total-cholesterol - HDL-cholesterol - LDL-cholesterol 


\section{Patients with type 2 diabetes}
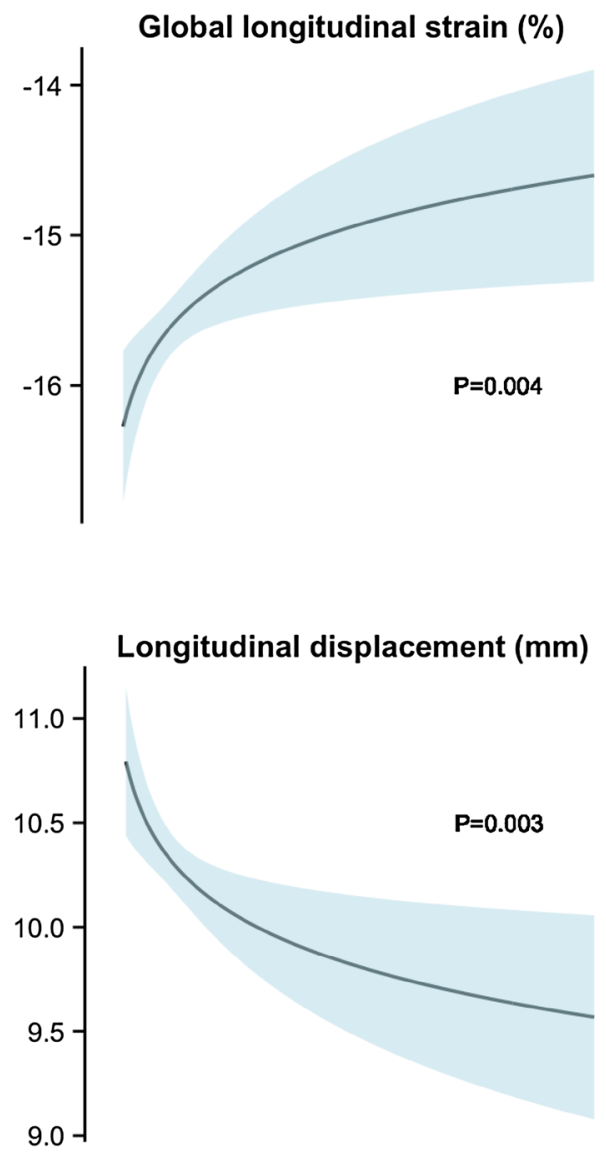

Density (n)

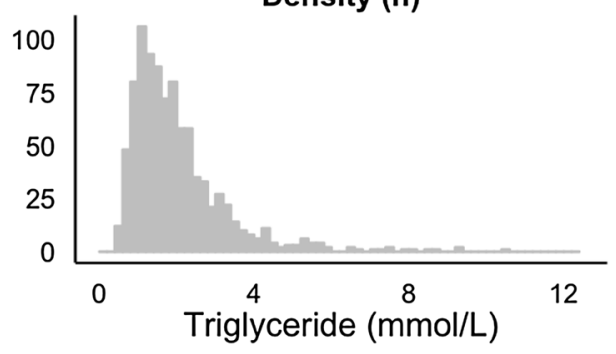

Patients with type 2 diabetes and receiving statin therapy
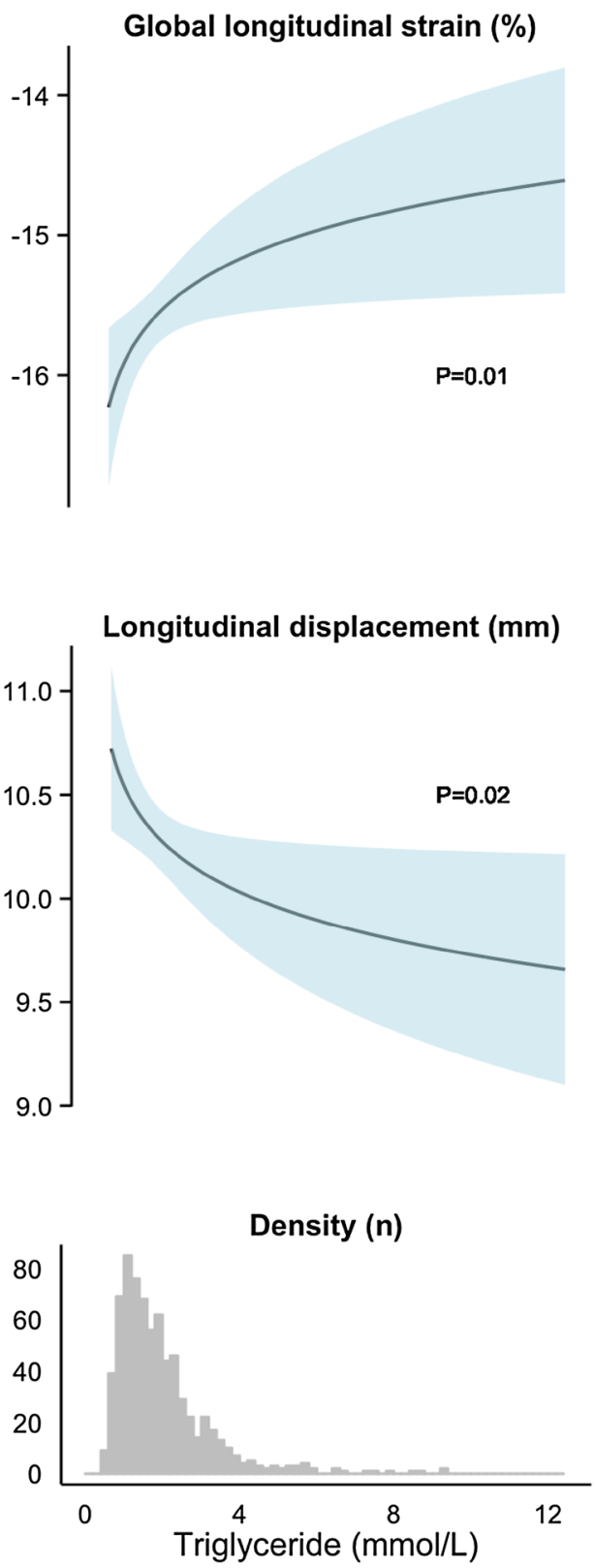

Fig. 2 Association of triglyceride levels to global longitudinal strain and longitudinal displacement in patients with type 2 diabetes and in patients with type 2 diabetes receiving statin therapy. The upper curves depict the predicted value with $95 \%$ confidence interval of GLS and longitudinal displacement for increasing levels of triglycerides on the original scale for both all patients and patients receiving statin therapy. The lower histograms are the distribution of triglycerides in all patients and patients receiving statin therapy

[25] studied the clinical features of decreased GLS in 144 patients with diabetes and found that among others hypertriglyceridemia was closely associated with low GLS. In patients with hypertension, hypercholesterolemia and low levels of HDL-cholesterol have been linked to increased LV mass [26, 27], and-in a mixed 
population-high levels of triglyceride were associated with increased LV mass index and decreased diastolic function expressed as lower e', E/A ratio and longer deceleration time and isovolumetric relaxation time [28]. In accordance with these studies, we found increased LV mass with increasing levels of triglyceride (that is inversely related to HDL-cholesterol), which however, was attenuated when performing multivariable adjustment. The opposite was the case, in the diastolic measurements, where we only found changes in e', peak $\mathrm{E}$ velocity and E/A ratio after multivariable adjustment. These differences may be explained by differences in patient populations and/or because of categorical cutoffs whereas we used continuous.

The influence of lipid levels on cardiac structure and incident heart failure has also been examined in the Framingham cohort. Though they did find a strong relationship between both non-HDL- and HDL-cholesterol levels and risk of heart failure in this population [29], they concluded, that there was no meaningful relationship between changes in LV structure and lipid levels. However, they did not examine any functional changes in the form of diastolic and systolic measurements [30]. In conclusion, our study is mainly in accordance with previous studies reporting a weak association of lipid levels and LV structure and diastolic function. In addition, our results suggests that the increased risk of heart failure related to dyslipidemia may be demonstrated in an early phase using sensitive measures of LV function including GLS and longitudinal displacement.

\section{Cholesterol remnants, triglycerides and longitudinal dysfunction as marker of early ischemic heart disease?}

Remnant lipoproteins are thought to cause atherosclerosis by mechanisms similar to LDL-cholesterol, which is by entering and accumulating in the intima of the arterial wall $[7,8]$, ultimately leading to coronary occlusion. Consequently, a number of studies have assigned an increased risk of coronary heart disease with increasing levels of triglycerides/cholesterol remnants [13, 31, 32]. However, as this is a slowly progressing process, it is likely, that only partial occlusion of the coronary arteries is present in the early stages of the disease affecting primarily the oxygen delivery to the distal parts of the coronary arteries. Here, in the subendocardial myofiber band, is where the longitudinal myocardial fibers are situated, and hence, the longitudinal function is thought to be the first to be affected in coronary atherosclerosis [9]. Therefore, measures of longitudinal function like GLS and longitudinal displacement are considered to be sensitive markers of early signs of the impact of atherosclerosis on cardiac function [33]. This is consistent with our findings where increasing levels of both triglyceride and cholesterol remnants were associated with decreasing longitudinal function, and in this light, it is possible that subclinical atherosclerosis in patients with high levels of cholesterol remnants and triglycerides is part of the explanation to the decreased longitudinal function we found in patients with type 2 diabetes. This is further supported by Wei et al. [34], who recently proposed myocardial steatosis as a mechanistic link between diastolic dysfunction and coronary microvascular dysfunction in women.

\section{Cholesterol remnants, triglycerides and accumulation of myocardial triglycerides}

At least one other mechanism may lead to decreased myocardial function with increasing levels of triglycerides and cholesterol remnants. In type 2 diabetes, excess availability of free fatty acids in the myocardium shifts the substrate for metabolism to almost entirely to rely on oxidation of free fatty acids, which in turn is thought to be a major cause of diabetic cardiomyopathy, that is, left ventricular impairment in patients with diabetes in the absence of coronary artery disease and hypertension [35]. Triglycerides are cleaved on the surface of lipoprotein remnants by the action of lipoprotein lipase present either in the endothelium or the intima of the coronary arteries [10]. In accordance, cardiac steatosis as measured by cardiac magnetic resonance spectroscopy has been shown to be present in patients with diabetes [36], and to be associated both with impairment in diastolic function [37] and systolic function expressed as decreased GLS with normal ejection fraction [38]. In addition, a study by Hammer et al. [39] showed that prolonged caloric restriction in obese patients with type 2 diabetes decreased myocardial triglyceride content and improved diastolic heart function. Also, this was accompanied by a decrease in fasting plasma-triglyceride and total-cholesterol levels. Taken together, these findings are very consistent with our findings that demonstrated deterioration of both diastolic (however vague) and systolic function with increasing levels of cholesterol remnants and triglyceride levels.

\section{Strengths and limitations}

This study is strong, in that it is a large cohort of patients with type 2 diabetes which is very well characterized with clinical characteristics, laboratory values and comprehensive echocardiography. Also, sample size is sufficiently large to perform sub-analyses of patients without known heart disease and-in particular-patients receiving statin therapy. However, the study has some limitations. Though the majority of patients had nonfasting lipid measurements a minority only had fasting 
lipids available. However, the association persisted when excluding patients with fasting lipid measurements from the analyses. Also, as this is an observational study, it is not possible to entirely rule out residual confounding.

\section{Conclusions}

In patients with type 2 diabetes, subtle decrease in left ventricular function is present with increasing levels of cholesterol remnants and triglyceride levels indicating an effect of these on cardiac function that is not detectable by conventional echocardiography. This association is present even in patients that are adequately treated with statin therapy. These findings support the notion of cholesterol remnants as possible therapeutic target in addition to statin therapy.

\section{Additional file}

Additional file 1: Table S1. Echocardiographic characteristics of all patients and patients receiving statin therapy. Table S2. Structural changes in relation to $\log _{2}(\mathrm{LDL}$ cholesterol). Table S3. Echocardiographic findings in patients without known coronary heart disease, $n=762$. Table S4. Echocardiographic findings in patients with known coronary heart disease, $\mathrm{n}=162$.

\section{Abbreviations}

BMI: body mass index; LV: left ventricular; LA: left atrial; E: peak early mitral inflow velocity; A: peak atrial mitral inflow velocity; E': early diastolic myocardial velocity; GLS: global longitudinal strain.

\section{Authors' contributions}

PGJ and JSJ designed the study. PGJ, MTJ and TFH collected and assisted in collecting the data, PGJ processed the data and drafted the manuscript. MTJ, RM, SG, TBS, TV, PR and JSJ contributed to the discussion and analyses of the data. All authors reviewed and critically edited the manuscript. All authors read and approved the final manuscript.

\section{Author details}

${ }^{1}$ Department of Cardiology, Herlev and Gentofte Hospital, University of Copenhagen, Kildegårdsvej 28, 2900 Hellerup, Denmark. ${ }^{2}$ Faculty of Health Sciences, Institute of Clinical Medicine, University of Copenhagen, Blegdamsvej 3B, 2200 Copenhagen N, Denmark. ${ }^{3}$ Steno Diabetes Center, Niels Steensens Vej 2-2, 2820 Gentofte, Denmark. ${ }^{4}$ Faculty of Health, Aarhus University, Nordre Ringgade 1, 8000 Aarhus C, Denmark. ${ }^{5}$ Center for Diabetes Research, Herlev and Gentofte Hospital, University of Copenhagen, Kildegårdsvej 28, 2900 Hellerup, Denmark.

\section{Acknowledgements}

The study was supported by the Carl and Ellen Hertz foundation.

\section{Competing interests}

Peter Rossing reports Grants from and shares in Novo Nordisk. Advisory boards in MSD, Astra Zeneca, Boehringer, Eli Lilly, Janssen, Novo Nordisk Astellas, Abbvie (all fees to institution). Lecture fee to institution from Bayer.

Tina Vilsbøll has received lecture fees from AstraZeneca, Boehringer Ingelheim, Bristol-Myers Squibb, Eli Lilly and Company, Merck Sharp \& Dohme, Novo Nordisk, Novartis, and Sanofi, and is a member of the Amgen, Advisory Boards of AstraZeneca, Boehringer Ingelheim, Bristol-Myers Squibb, Eli Lilly and Company, Merck Sharp \& Dohme, Novo Nordisk, and Sanofi.

\section{Availability of data and material}

The datasets during and/or analysed during the current study available from the corresponding author on reasonable request.

\section{Ethical statement and consent to participate}

The study was conducted in accordance with the Helsinki Declaration. The Danish National Committee on Biomedical Research Ethics, amendment to protocol no. H-3-2009-139. [40] Oral and written informed consent was obtained from all patients before inclusion.

\section{Funding sources}

The study was carried out as part of PGJ's employment at Gentofte Hospital, University of Copenhagen, Denmark.

Received: 9 August 2016 Accepted: 16 September 2016

Published online: 22 September 2016

\section{References}

1. Dale AC, Vatten LJ, Nilsen TI, Midthjell K, Wiseth R. Secular decline in mortality from coronary heart disease in adults with diabetes mellitus: cohort study. BMJ. 2008;337:99-102.

2. Lipscombe LL, Hux JE. Trends in diabetes prevalence, incidence, and mortality in Ontario, Canada 1995-2005: a population-based study. Lancet Lond Engl. 2007:369:750-6.

3. Preis SR, Hwang S-J, Coady S, Pencina MJ, D'Agostino RB, Savage PJ, et al. Trends in all-cause and cardiovascular disease mortality among women and men with and without diabetes mellitus in the framingham heart study, 1950 to 2005. Circulation. 2009;119:1728-35.

4. Gregg EW, Li Y, Wang J, Rios Burrows N, Ali MK, Rolka D, et al. Changes in diabetes-related complications in the United States, 1990-2010. N Engl J Med. 2014;370:1514-23.

5. Jørgensen AB, Frikke-Schmidt R, West AS, Grande P, Nordestgaard BG, Tybjærg-Hansen A. Genetically elevated non-fasting triglycerides and calculated remnant cholesterol as causal risk factors for myocardial infarction. Eur Heart J. 2013;34:1826-33.

6. Varbo A, Benn M, Tybjærg-Hansen A, Jørgensen AB, Frikke-Schmidt R, Nordestgaard BG. Remnant cholesterol as a causal risk factor for ischemic heart disease. J Am Coll Cardiol. 2013;61:427-36.

7. Nordestgaard BG, Wootton $\mathrm{R}$, Lewis $B$. Selective retention of $V L D L$, IDL, and LDL in the arterial intima of genetically hyperlipidemic rabbits in vivo molecular size as a determinant of fractional loss from the intima-inner media. Arterioscler Thromb Vasc Biol. 1995;15:534-42.

8. Shaikh M, Wootton R, Nordestgaard BG, Baskerville P, Lumley JS, Ville AEL, et al. Quantitative studies of transfer in vivo of low density, Sf 12-60, and Sf 60-400 lipoproteins between plasma and arterial intima in humans. Arterioscler Thromb Vasc Biol. 1991:11:569-77.

9. Stanton T, Marwick TH. Assessment of subendocardial structure and function. JACC Cardiovasc Imaging. 2010;3:867-75.

10. Goldberg IJ, Eckel RH, McPherson R. Triglycerides and heart disease, still a hypothesis? Arterioscler Thromb Vasc Biol. 2011;31:1716-25.

11. Bayeva M, Sawicki KT, Ardehali H. Taking diabetes to heart-deregulation of myocardial lipid metabolism in diabetic cardiomyopathy. J Am Heart Assoc. 2013;2:e000433.

12. Boudina S, Abel ED. Diabetic cardiomyopathy revisited. Circulation. 2007:115:3213-23.

13. Nordestgaard BG, Benn M, Schnohr P, Tybjærg-Hansen A. Nonfasting triglycerides and risk of myocardial infarction, ischemic heart disease, and death in men and women. JAMA. 2007;298:299-308.

14. Ebong IA, Goff DC, Rodriguez CJ, Chen H, Sibley CT, Bertoni AG. Association of lipids with incident heart failure among adults with and without diabetes mellitus multiethnic study of atherosclerosis. Circ Heart Fail. 2013;6:371-8

15. Miselli M-A, Nora ED, Passaro A, Tomasi F, Zuliani G. Plasma triglycerides predict ten-years all-cause mortality in outpatients with type 2 diabetes mellitus: a longitudinal observational study. Cardiovasc Diabetol. 2014;13:135

16. Jørgensen PG, Jensen MT, Mogelvang R, Fritz-Hansen T, Galatius S, Biering-Sørensen T, et al. Impact of type 2 diabetes and duration of type 2 diabetes on cardiac structure and function. Int J Cardiol. 2016;221:114-21.

17. Liu J-H, Chen Y, Yuen M, Zhen Z, Chan CW-S, Lam KS-L, et al. Incremental prognostic value of global longitudinal strain in patients with type 2 diabetes mellitus. Cardiovasc Diabetol. 2016;15:22. 
18. Jørgensen PG, Jensen MT, Mogelvang R, von Scholten BJ, Bech J, FritzHansen T, et al. Abnormal echocardiography in patients with type 2 diabetes and relation to symptoms and clinical characteristics. Diab Vasc Dis Res. 2016;13:321-30.

19. Varbo A, Benn M, Smith GD, Timpson NJ, Tybjaerg-Hansen A, Nordestgaard BG. Remnant cholesterol, low-density lipoprotein cholesterol, and blood pressure as mediators from obesity to ischemic heart disease. Circ Res. 2015;116:665-73.

20. Lang RM, Badano LP, Mor-Avi V, Afilalo J, Armstrong A, Ernande L, et al. Recommendations for cardiac chamber quantification by echocardiography in adults: an update from the American Society of Echocardiography and the European Association of Cardiovascular Imaging. Eur Heart J Cardiovasc Imaging. 2015;16:233-70.

21. de Knegt MC, Biering-Sorensen T, Sogaard P, Sivertsen J, Jensen JS, Mogelvang R. Concordance and reproducibility between M-mode, tissue Doppler imaging, and two-dimensional strain imaging in the assessment of mitral annular displacement and velocity in patients with various heart conditions. Eur. Heart J. -. Cardiovasc Imaging. 2014;15:62-9.

22. Huang Y, Walker KE, Hanley F, Narula J, Houser SR, Tulenko TN. Cardiac systolic and diastolic dysfunction after a cholesterol-rich diet. Circulation. 2004;109:97-102.

23. Liu L, Mu Y, Han W, Wang C. Association of hypercholesterolemia and cardiac function evaluated by speckle tracking echocardiography in a rabbit model. Lipids Health Dis. 2014;13:128.

24. Wang T-D, Lee C-M, Wu C-C, Lee T-M, Chen W-J, Chen M-F, et al. The effects of dyslipidemia on left ventricular systolic function in patients with stable angina pectoris. Atherosclerosis. 1999;146:117-24.

25. Mochizuki Y, Tanaka H, Matsumoto K, Sano H, Toki H, Shimoura H, et al. Clinical features of subclinical left ventricular systolic dysfunction in patients with diabetes mellitus. Cardiovasc Diabetol. 2015;14:37.

26. Horio T, Miyazato J, Kamide K, Takiuchi S, Kawano Y. Influence of low highdensity lipoprotein cholesterol on left ventricular hypertrophy and diastolic function in essential hypertension. Am J Hypertens. 2003:16:938-44.

27. Schillaci G, Vaudo G, Reboldi G, Verdecchia P, Lupattelli G, Pasqualini L, et al. High-density lipoprotein cholesterol and left ventricular hypertrophy in essential hypertension. J Hypertens. 2001;19:2265-70.

28. de lasFuentes $L$, Waggoner AD, Brown AL, DávilaRomán VG. Plasma triglyceride level is an independent predictor of altered left ventricular relaxation. J Am Soc Echocardiogr. 2005;18:1285-91.
29. Velagaleti RS, Massaro J, Vasan RS, Robins SJ, Kannel WB, Levy D. Relations of lipid concentrations to heart failure incidence: the Framingham Heart study. Circulation. 2009;120:2345-51.

30. Velagaleti RS, Pencina MJ, Vasan RS, Benjamin EJ, Massaro JM, Pencina K, et al. Cross-sectional associations of lipid concentrations to left ventricular structural attributes. Am J Cardiol. 2010;105:1297-9.

31. Ørgen Jeppesen J, Hein HO, Suadicani P, Gyntelberg F. Triglyceride concentration and ischemic heart disease an eight-year follow-up in the Copenhagen Male study. Circulation. 1998;97:1029-36.

32. Di Angelantonio E, Sarwar N, Perry P, Kaptoge S, Ray KK, Thompson A, et al. Major lipids, apolipoproteins, and risk of vascular disease. JAMA. 2009;302:1993-2000

33. Shah AM, Solomon SD. Myocardial deformation imaging current status and future directions. Circulation. 2012;125:e244-8.

34. Wei J, Nelson MD, Szczepaniak EW, Smith L, Mehta PK, Thomson LEJ, et al. Myocardial steatosis as a possible mechanistic link between diastolic dysfunction and coronary microvascular dysfunction in women. Am J Physiol Heart Circ Physiol. 2016;310:H14-9.

35. van de Weijer T, Schrauwen-Hinderling VB, Schrauwen P. Lipotoxicity in type 2 diabetic cardiomyopathy. Cardiovasc Res. 2011;92:10-8.

36. McGavock JM, Lingvay I, Zib I, Tillery T, Salas N, Unger R, et al. Cardiac steatosis in diabetes mellitus a $1 \mathrm{H}$-magnetic resonance spectroscopy study. Circulation. 2007;116:1170-5.

37. Rijzewijk LJ, van der Meer RW, Smit JWA, Diamant M, Bax JJ, Hammer S, et al. Myocardial steatosis is an independent predictor of diastolic dysfunction in type 2 diabetes mellitus. J Am Coll Cardiol. 2008:52:1793-9.

38. Ng AC, Delgado V, Bertini M, van der Meer RW, Rijzewijk LJ, Hooi Ewe S, et al. Myocardial steatosis and biventricular strain and strain rate imaging in patients with type 2 diabetes mellitus. Circulation. 2010;122:2538-44.

39. Hammer S, Snel M, Lamb HJ, Jazet IM, van der Meer RW, Pijl H, et al. Prolonged caloric restriction in obese patients with type 2 diabetes mellitus decreases myocardial triglyceride content and improves myocardial function. J Am Coll Cardiol. 2008:52:1006-12.

40. Jensen MT, Sogaard P, Andersen HU, Bech J, Hansen TF, Galatius S, et al. Prevalence of systolic and diastolic dysfunction in patients with type 1 diabetes without known heart disease: the Thousand \&1 Study. Diabetologia. 2014;57:672-80

\section{Submit your next manuscript to BioMed Central and we will help you at every step:}

- We accept pre-submission inquiries

- Our selector tool helps you to find the most relevant journal

- We provide round the clock customer support

- Convenient online submission

- Thorough peer review

- Inclusion in PubMed and all major indexing services

- Maximum visibility for your research

Submit your manuscript at www.biomedcentral.com/submit
BioMed Central 